\title{
ERRATUM
}

\section{Erratum to: Introduction of Breadfruit (Artocarpus altilis) to the Hawaiian Islands}

\author{
Mark D. McCoy*,1, Michael W. Graves ${ }^{2}$, and Gail Murakami ${ }^{3}$ \\ ${ }^{2}$ University of Otago, Dunedin, New Zealand \\ ${ }^{3}$ University of New Mexico, Albuquerque, NM, USA \\ ${ }^{4}$ International Archaeological Research Institute, Inc., Honolulu, HI, USA \\ ${ }^{*}$ Corresponding author; e-mail: mark.mccoy@otago.ac.nz
}

\section{Erratum to: Econ Bot}

DOI 10.1007/s12231-010-9140-1

In Volume 64, Number 3, page 375, end of first paragraph, "gourd (Curcurbita pepo)" should be "bottle gourd (Lagenaria siceraria)".

The online version of the original article can be found at http://dx.doi.org/10.1007/s12231-010-9140-1

${ }^{1}$ Published online 20 August 2011. 